Stream: Inspiring Critical Thought

2018, Vol 10(2), 1-14

(C) The Author(s), 2018

http://journals.sfu.ca/stream

\title{
Time-Space Analysis of Facebook News Feeds
}

\author{
Felix Lo \\ School of Communication \\ Simon Fraser University
}

\begin{abstract}
In the 20th century, several scholars across different disciplines have explored the relations between sociality and the associated perceptions of time and space. This paper draws on their theories to study how the Facebook News Feed feature inscribes users with a certain kind of temporality and spatiality. Building on Manual Castells' characterization of online activities as a "temporal collage," it argues that, through the interactions with News Feeds, users encounter the desequencing of the temporality of their social space. It further analyzes a News Feed page as a temporal object as defined by Bernard Stiegler, and adopts his critique of cinematic time to reveal how this feature inscribes an "always on" behavior for users even when they are offline. It concludes by discussing the political significance of this temporality and spatiality in two different senses: the constant acceleration in the pace of life and online surveillance. It draws on David Harvey's concept of spacetime compression to discuss the relations between the temporality of Facebook and capitalism, and on Anthony Gidden's time-space distantiation to discuss the power relations of online surveillance.
\end{abstract}

\section{Keywords}

temporality, spatiality, time-space acceleration, time-space distanciation, social media, retention and protention, networked individual, online surveillance

\section{Introduction}

A few years ago I went on a ski trip at Kelowna with a few old buddies. After several rounds of skiing in the morning, we stopped by a restaurant for lunch while taking a much-needed break. Upon discovering the availability of public Wi-Fi at the restaurant, one of us took a selfie and posted the picture, along with all the pictures we took in the morning, to Facebook. Given that our tavern was also offering free $\mathrm{Wi}-\mathrm{Fi}$, he could have gone through the tedious motions of uploading his pictures at the end of the day. Unlike a labourer in a capitalist market, his urge to instantaneously connect his activities with others over the Facebook News Feed feature cannot be explained by the lure of monetary reward or the fear of penalty. What then are the drivers behind this perpetual production and distribution of content at any time and in any place?

While the political movements organized on a social media platform may prompt the suggestion that social media is politically emancipatory, I want to examine social media from another perspective, that of a temporal-spatial analysis. To conduct an inquiry about these ubiquitous online activities, we ought to take into account how the temporal and spatial perceptions have evolved in the past, that is, how the historical reconfigurations of symbolic and materialistic relations have induced changes in temporality and spatiality. Since the late $20^{\text {th }}$ century, scholars across different fields have explored the relations between sociality and the associated perceptions of time and 
space. The sociologist Anthony Giddens describes the stretching of social systems across space and time $(1981,1984)$. The geographer/cultural theorist David Harvey maps the compression of time and space to specific historical moments during the capitalist expansion (1989). The urban sociologist Manuel Castells identifies a new logic of perceiving space-time in a networked social structure (2007, 2010, 2012). The philosopher Bernard Stiegler explains how the media and cultural industry constructs selective memories in the human consciousness $(1998,2009,2011)$. The sociologist Henri Lefebvre develops the notion of "social space" (1991). Their works reveal the different ways that temporal and spatial frames are manipulated to reconfigure power relations.

This paper is primarily a theoretical analysis of the temporality and spatiality of Facebook users, focusing specifically on the behavior of reading News Feed stories and of posting personal status. Drawing from the theories by Lefebvre, Giddens, Harvey, Castells and Stiegler, I want to address the following questions: How does the News Feed feature condition the temporal and spatial relations of Facebook users, and what are the social and political significance of these relations? The first section is a brief synopsis of these theories, which depart from the intuitive concepts of the Euclidean space and the mechanical clock-time. They form the basis of my analysis for the rest of the paper. In the second section, I characterize a News Feed page on Facebook as a temporal object with a "rolling present." I also label individuals who consume and produce stories as "network individuals" because their temporalities are intertwined with their friends' activities. In the third section, I present how Stiegler analyzes cinematic time based on his concepts of "retention" as ephemeral memory and of "protention" as future anticipation. Since a News Feed page is also a temporal object, I draw from Stiegler's concepts to explain how the activities of reading News Feed stories and of posting status can inscribe "protentions" to users. In the final section, I argue that this inscription of protention is politically significant in two senses. First, because this commodity constantly accelerates the pace of life, Harvey's sociopolitical analysis on space-time compression is applicable. Thus, just as space-time compression assists the growth of capitals of the capitalist economy, so do the online activities in News Feeds. Second, the awareness of being watched regulate both online and offline behavior in users. By referring to works of Siva Vaidhyanathan and Michel Foucault, I compare this surveillance of the News Feed feature with panopticism and the googlization of everything.

\section{Theoretical Framework for Time-Space Analysis}

According to Giddens, analyses of time and space traditionally do not belong to the discipline of social analysis (1981, p. 30). They used to be the concerns of philosophy, history, and geography until the early $20^{\text {th }}$ century. The meaning of time is traditionally the concern of philosophers and historians. Philosophers deal with the temporality of an individual. They are concerned with how consciousness perceives the passing of time. Historians are concerned with collective temporality such as short durée or longue durée. Social elites can manipulate an individual or a collective temporality by conditioning which events to remember. Hence for both disciplines, the manipulation of selective memory shapes temporality.

In the latter half of $20^{\text {th }}$ century, social theorists began to formulate their own theories by appropriating the philosophical, historical, and geographical theories of time and space. Giddens formulates his social theory of structuralism and power relations in the concept of time-space distanciation (1981). According to Giddens, "institutions are practices that 'stretch' over long time-space distances in the reproduction of social system" (1981, p. 28). Harvey builds on Giddens' time-space distanciation in The Condition of Postmodernity (1989, p. 22). He traces several historical moments from the $19^{\text {th }}$ century to the late $20^{\text {th }}$ century. Each of these moments was accompanied by a cultural tension that resulted from the pressure of accelerating product life cycles under the ideology of 
perpetual capitalist growth (1989, pp. 201-307). The latest of these moments corresponds to the process of globalization in the postmodern condition. In The Rise of Network Society (2010), Castells proposes the forming of a network structure in globalization. He analyzes a large collection of empirical data for discussing Giddens's and Harvey's theories. In addition, he identifies a new logic of space-time in a network society where the dominant media is built upon the multi-national digitalnetwork (2010). With the instantaneousness of accessing collective and personal histories, the mediated experiences of reality are desequenced into a temporal perception that Castells calls "timeless time" (2010, pp. 461-499). Following a different lineage of thinkers, Stiegler revisits the philosophies of Kant, Husserl and Heidegger in an inquiry about how time-consciousness has been the subject of hegemonic control of the media and cultural industry (2011). While this conclusion is similar to that in The Dialectic of Enlightenment (2002) by Horkheimer and Adorno, he differentiates from their work by examining films as temporal objects (2011, pp. 35-78). Just as a montage in filmmaking expresses meanings through a selective ensemble of scene cuts, the human consciousness constructs meanings and identities by selectively remembering personal experiences and social narratives.

Matching this relationship between social institutions and time is the sociology of space by Henri Lefebvre. Lefebvre distinguishes a social space from a physical or mental space. It is the space of social practice occupied by sensory phenomena (1991, p. 12). According to Lefebvre, a social space can be produced to facilitate interactions and social relation (1991, p. 16). In other words, specific arrangements of a physical space can result in the production of a social space. The design and construction of physical objects can demarcate social boundaries and configure the flows of materials or information in physical space. For example, a bridge, a building's interior space, or a public plaza can condition social behavior by reconfiguring physical boundaries. In digital communication, the digital network is the physical substance that set up virtual bridges between humans and institutions. As a digital communication system, Facebook is a virtual social space that operates materialistically as a morphing configuration of electrons, silicon or radio waves. In Castells' articulation, a new form of space, which he calls the "space of flows," is carved into physical reality using the materials of cables and wires, allowing instant communications of social relations and easy accesses to historical archives (2010, pp. 407-459).

For the rest of this paper, I shall build on these social theories on temporality and spatiality to examine the News Feed feature. I refer to Castells' theories to argue that a News Feed page is a networked temporal collage. I then draw from Stiegler's philosophy of cinematic time to analyze the temporality of reading News Feed stories and of posting status. This temporality reveals a propensity of constant acceleration of life space that follows the pattern of space-time compression in Harvey's works. This similarity allows us to see the connection between such temporality and capitalism. Another political significance is online surveillance, and the theories of space by Giddens and by Lefebvre help illuminate power relations through instituted manipulations of a social space and time.

\section{Networked Temporal Collage of a News Feed page}

The interface design of Facebook has undergone a series of changes since its inception in 2004. Facebook introduced the News Feed and Mini-Feed features in 2006 ("Facebook Gets a Facelift," 2006) and the Like feature in April 2010 (Gelles, 2010). The News Feed feature appears on the homepage of each account, whereas Mini-Feed appears on the wall of each person's profile. Facebook introduced these features to support a new way of looking at friends' news. The product manager for the features gave this description shortly after the feature was launched: 
News Feed highlights what's happening in your social circles on Facebook. It updates a personalized list of news stories throughout the day... whenever you log in, you'll get the latest headlines generated by the activity of your friends and social groups ... Mini-Feed is similar, except that it centers around one person. Each person's Mini-Feed shows what has changed recently in their profile and what content (notes, photos, etc.) they've added. ("Facebook Gets a Facelift," 2006)

The News Feed and Mini-Feed features are innovations that are derived from typical system designs. ${ }^{1}$ Most systems are designed to store activity logs only because system administrators can use them to troubleshoot technical problems. Basic users are ignorant of the existence of these logs. The News Feed and Mini-Feed features bring these hidden logs to the foreground.

The innovation brings forth a new layer of social network relations. The old layer is composed of nodes that represent individuals' avatars. The new layer operates at a different degree of granularity, where News Feed stories are the network nodes and each account's News Feed page is a hub connected with these nodes. This new layer of network relations reflects more closely of how individuals actually relate one another. Individuals become associated with one another through shared experiences in a common social space. At the same time, the News Feed feature operates differently from a social group or an online forum. Members of a social group share the same collection of stories. In contrast, each News Feed page is a personalized list of shared stories. Therefore, instead of classifying a News Feed page as a social space, I characterize it as a personal space of an individual. ${ }^{2}$ A Mini-Feed is a record of personal experiences outside of Facebook such as attending a concert or playing computer games. A News Feed page is an aggregate of Mini-Feeds. It is a collection of Facebook events that mediate friends' activities and opinions in the actual life-worlds. It is a personal lens of an individual's social relations. These personalized and social qualities differentiate the News Feed feature from public news broadcast. News broadcast represents the collective history of its audiences, whereas the News Feed feature collects the personal social history of an individual.

The user interface of the News Feed and Mini-Feed features further shapes this personal experience into a temporal experience. ${ }^{3}$ The user interface gives the resemblance of a temporal flow. This resemblance is discernible by comparing the features with an online forum. In an online forum, the messages in each topic thread are sorted in a chronological order. The user interface typically provides users with hyperlinks to navigate to the next few pages, the previous few pages, or the last page. Sometimes a user wants to jump to the last page and go through the pages in reverse orders, but the messages on each page are still sorted by posted timestamps. Messages are typically related to older messages as their responses or comments. The user interface of a News Feed page provides a different arrangement of friends' stories. These stories are independent from one another, and the latest stories usually appear near the top of the page. As a user scrolls down to read older stories and reaches the end of the page, the Javascript code embedded in the HTML page will request older stories from the server and append them to the end of the page. Despite its inefficiency in searching, this design evokes the temporality of a "rolling present," a concept I borrow from the analysis of an

${ }^{1}$ The U.S. Patent and Trademark Office (USPTO) has granted Facebook the following patent for News Feed: U.S. Patent No. 8,171,128 - "Communicating a newsfeed of media content based on a member's interactions in a social network environment" - Filed on August 11, 2006, and granted on May 1, 2012.

2 In Networked: the New Social Operating System (2012), Rainie and Wellman study people's interactions as they increasingly incorporate gadgets into their lives. Their result also indicates that interactions no longer take place in groups but on personal-centric networks which are "multiuser, multitasking and multithreaded" (p. 6).

3 The user interface design of the News Feed feature has changed a few times since its initial inception. Its evolution is beyond the scope of this paper. Future research can trace its evolution through the patents that Facebook have applied for the News Feed feature. 
online forum by Xin and Feenberg (Xin, Glass, Feenberg, Bures, \& Abrami, 2010). Xin and Feenberg argue that, unlike printed publications, forum design tends to hinder easy movement between the current activity and older material. Thus they use this term "rolling present" to convey the forgetfulness of the virtual past. The News Feed feature takes this forgetfulness one step further. The longer-term past is practically irretrievable. A user needs to scroll for a long time to find a story from the previous year. ${ }^{4}$ In addition, the "rolling" metaphor matches the continuity in scrolling down a page that provides no "Next" or "Prev" button. This "rolling present," with transitory memories irretrievably fading away, has the form of a temporal object similar to Stiegler's film example.

Even though a News Feed page has the manifestation of a "rolling present," not all stories are sorted chronologically. By default, the page displays stories based on the Top News algorithm. The algorithm calculates the relevance of a story based on its posting timestamp along with the number of comments or Likes ("Facebook Tips: What's the Difference between Top News and Most Recent?," 2010). If a user keeps the default configuration, the News Feed page would display stories sorted from the highest to the lowest relevance ratings. In other words, stories are desequenced according to a relatively mysterious function. When an individual scrolls through the page, she or he perceives a temporal flux in a desequenced order. The temporal and desequenced perceptions conflict with one another, inducing a temporal ambiguity. The ambiguity confuses the time-consciousness in an individual. This temporal confusion brings to mind what the theory of "timeless time" by Castells (2010, pp. 461-499). According to Castells:

The mixing of times in the media, within the same channel of communication and at the choice of the viewer/interactor, creates a temporal collage, where not only genres are mixed, but their timing becomes synchronous in a flat horizon, with no beginning, no end, no sequence. (2010, p. 492)

The "temporal collage" is a metaphor of overlapping events with no clear boundaries. Its "rolling present" is a "flat horizon" of recent activities, and the horizon has "no beginning, no end, no sequence." Based on Castells' definition, a News Feed page is a temporal collage even if a user changes the default configuration to sort chronologically. First, the feed displays the posts of possibly concurrent activities with different starting and ending points. Second, the chronological sequence is based on the timestamps of the posts instead of when the activities commence. In addition, whereas Castells assumes that media would provide users with choices that can determine the mixture of time, a News Feed page affords no such choices. On YouTube, viewers can retrieve a video from thirty years ago as easily as one from last year. For viewers who grew up in a modernist culture, a temporal collage conflicts with the clock-calendar temporal frame. To act consistently with their modernist tendency, they have the options to play the videos according to a chronological order. In contrast, viewers of their News Feed pages have no alternative. They must accept the temporal collage, which is codified and reified into the technical base.

As I mentioned earlier, friends' stories on a News Feed page are intertwined in a personalcentric network. Therefore, the temporal collage of a News Feed page is a networked temporal collage. Stiegler argues that, owing to the similarity between time-consciousness and temporal flow in a film montage, a cinematic temporal object can condition its viewers' time-consciousness $(2011, \mathrm{p}$. 17). This argument is applicable to a News Feed page, as its networked temporal collage can condi-

\footnotetext{
${ }^{4}$ Since 2011, Mini-Feed supports a Timeline feature that allows readers to jump to a particular year, but not month or date, so the mechanism for recalling a story is available if a user remembers who posted the story. But within a single year there may still be many stories, and users still need to scroll for a long time before finding a target story.
} 
tion a user's time-consciousness. Whereas a cinematic temporal object conditions collective behaviors (Stiegler, 2011, pp. 35-78), a networked temporal collage conditions an individual's timeconsciousness. It conditions the individual such that it feels interconnected with friends' activities. The individual is no longer isolated, but goes through daily life consisting of shared experiences among friends. ${ }^{5}$ Appropriating the terminology "networked individuals" coined by Lee Rainie and Barry Wellman (2012), I label individuals as "networked individuals" in this paper if their timeconsciousness is intertwined with friends' events in a networked temporal collage. ${ }^{6}$ Whereas Rainie and Wellman focus on social behavior of a networked individual, my analysis is concerned with time-consciousness. When individuals read their News Feed pages, their time-consciousness would adopt friends' stories as if these stories belong to themselves. The concept of a networked time-consciousness can help explain how users develop the temporality of reading News Feed stories and of posting status on Facebook.

\section{Temporality of Reading News Feed Stories and of Posting Status on Facebook}

Since a News Feed page fits the characteristics of a "temporal object" as defined by Stiegler, we may appropriate his philosophy of cinematic time to the temporality of reading News Feed stories and of posting status on Facebook. In this section, I begin by explaining Stiegler's explication of time and memory as well as his definition of a temporal object. I then apply these concepts to analyze the temporality of reading and posting on Facebook.

\section{A. Primary Retention, Secondary Memory, and Protention}

In his inquiry into time and consciousness, Stiegler builds on the works of Husserl to whom the temporality of all consciousness is a flux. Husserl first distinguishes a temporal object from other objects: "A temporal object is formed temporally ... not completely unfolded, completely past but still passing (i.e. temporal)" (Stiegler, 2011, p. 14). The clock and calendar are the temporal objects that induce a scheduling framework in industrial capitalism. In every culture, only certain spatial and temporal frameworks are acceptable. Individuals within a culture internalize its acceptable frameworks through the exposure to education and media.

To understand how a temporal framework is internalized, Husserl studies the temporal object of a melody and discovers primary retention (Stiegler, 2011, p. 13). Primary retention is not the kind of memory that can be recalled, which Husserl calls "secondary memory." Rather, it is an originary association between the now and the "just-past" which remains present in the now (Stiegler, 2011, pp. 14-15). This association can best be illustrated by describing the perceptual experience in hearing a melody:

When I hear a melody, as a temporal object it presents itself to me as it unfolds. In the course of this process each note that is presented now retains in itself the preceding note, which itself retains the preceding one, etc. The current note contains within it all preceding notes ... This continuity is the temporal object's unity. Because the sonorous now retains all the notes

\footnotetext{
${ }^{5}$ Entrepreneurs capitalized on this growing desire to share experiences instantaneously and founded Foursquare in 2009 and Instagram in 2010.

${ }^{6}$ The "networked individual," as I define it, also differs from Gergen's concept of multiphrenia in his book The Saturated Self (Gergen, 1991, pp. 73-80). This concept, which Turkle applies in her study of MUD in Life on the Screen (1997), is concerned with multiple avatars without a "true self" at the centre (p. 257). In contrast, a networked individual is "personal-centric," thus single and not multiple.
} 
preceding it, the present note can sound melodic, can be "musical," whether it is harmonic or unharmonic: it continues to be properly a note and not merely a sound or a noise. (Stiegler, 2011, p. 14)

Where Stiegler departs from Husserl is the question of whether primary retention is grounded totally and uniquely on perception, or whether it can be a product of conscious selections (Stiegler, 2011, p. 17). Stiegler argues that it is a product of conscious selections by appealing to the experience of hearing the same melody twice. Consciousness processes the same melody differently between the first and the second hearing, and each subsequent hearings of the same melody provide a new phenomenon, "richer if the music is good, less rich if bad" (Stiegler, 2011, p. 17). Husserl argues that a sound is musical because the "sonorous now retain all the notes preceding it," but in fact only a selection of preceding notes are retained in the primary memory. This selection can be shaped by the secondary memory, such as the recollection of a previous hearing of the repeated melody. The criteria or schemata for selectively retaining 'just-past' sensory experiences are themselves the products of selections from secondary memory (Stiegler, 2011, p. 19).

The second hearing of a melody consists not only of retention but also of protentions, as the next note can be anticipated thanks the recollection of a previous hearing (Stiegler, 2011, p. 19). Hence the secondary memory affects not only the perception of "sonorous now" through selected retention of previous notes, but also the projection/protention/anticipation of what comes next in the immediate future. A first time listener to Beethoven Symphony No. 5 cannot anticipate E-flat as the fourth note (G...G...G...E-flat), but the familiarization of this famous symphony cultivates the anticipation of this tune. Audiences would find it comical if an orchestra abruptly plays a different fourth note other than E-flat. ${ }^{7}$

By analyzing the phenomena of an ephemeral past, Stiegler extends Husserl's philosophy to identify the relationship between a temporal experience and the human memory. He classifies memory into primary retention, secondary memory, and protention. Based on this classification, he illustrates how a temporal object can shape consciousness (Stiegler, 2011, p. 17). Since I argue that a News Feed page exhibits a networked temporal collage, it fits the characteristics of a temporal object as defined by Stiegler. Therefore, his classification of primary retention, secondary memory, and protention is applicable to the analysis of the News Feed feature.

\section{B. Protention of Reading News Feed stories}

Building on Stiegler's theory on a temporal object, I identify four moments of how users develop the protention of reading News Feed stories. In the first moment, users develop their protentions according to their social needs. In the second moment, users develop their protentions through the curiosity of unread stories. In the third moment, repeated usages shape users protentions into a regular routine. In the fourth moment, users immerse into the networked temporal flow of their News Feed pages and adopt friends' stories as constituents of their own experiences.

The News Feed feature is a platform that provides users with an awareness of friends' activities. By keeping up-to-date with the stories on a News Feed page, users are also keeping themselves so-

${ }^{7}$ Castells has written a similar remark in his description of real virtuality: "[B]ecause they are the symbolic fabric of our life, the media tend to work on consciousness and behavior as real experience works on dreams, providing the raw material out of which our brain works. It is as if the world of visual dreams (the information/entertainment provided by television) would give back to our consciousness the power to select, recombine, and interpret the images and sounds that we have generated through our collective practices or by our individual preferences." (2010, p.365) 
cially up-to-date. For users with enough active Facebook friends, it will be difficult for them to find an event that happened a week ago. As a result, if they fail to catch the evanescent "present" on Facebook, they will probably miss those moments completely. They may hear some stories directly from friends or relive these moments by navigating into a particular friend's profile, but they still miss many stories. Therefore, the secondary memory of socially relevant stories shapes the protention to read News Feed stories.

Users also develop their protention through the curiosity of unread stories. If a user has five hundred active friends who share around one post per day, the user's personal News Feed page would be updated with around one post every three minutes. After repeated usage, a user will acquire an awareness of the feed's update frequency. The secondary memory of repeated usage shapes the anticipation of unread stories as time elapses. After idling from Facebook for some time, the unsatisfied anticipations intensify the curiosity of unread stories. This curiosity contributes to a protention to read News Feed stories. The protention is similar to that in reading the latest messages in an online forum. The difference lies only in the type of curiosity. One is socially motivated while the other is special interest driven.

Repetitive usages further shape the protention into a habit. The regularity of reading News Feed stories varies according to personalities or circumstances. A user who has more than a thousand active Facebook friends would have many News Feed stories to read. If a person's job requires working with the computer all day, then she or he can frequently switch between working and browsing the News Feed page. By frequently reading News Feed stories, the person would develop a habit of being updated with the latest stories. This habit resembles the habitual practices in a temporal cycle, such as calendar-time, clock-time, or watching the TV news at $11 \mathrm{pm}$ everyday. Temporal cycles are techniques that a modern society employs to co-ordinate social activities. After repeated exposure to temporal cycles, a viewer will internalize these cycles. The temporal awareness of the approximate clock-time of $11 \mathrm{pm}$ engenders the protention of watching the TV news. In Stiegler's terminology, the internalization creates the selection criteria of primary retention. This retention is similar to the audio retention of a musical harmony. The habit to read News Feed stories is also a reconfiguration of one's temporal frames. One's primary retention has selectively retained one's typical frequency of reading the News Feed page. Suppose the frequency is thirty minutes per visit. The temporal awareness of the passing of approximately thirty minutes would engender the protention to read the News Feed page.

In the fourth moment, users immerse into the networked temporal flow of their News Feed pages and adopt their friends' stories as their own. This personalized affordance intensifies the protention to read News Feed stories. As I previously argue, the News Feed user interface inscribes users with a memory that can be characterized as a networked temporal collage. By frequently browsing the News Feed page, a user becomes a networked individual who is always aware of friends' activities on Facebook. This awareness is different from the anticipation of friends' updates on the News Feed page. The subtle difference lies in the adoption of such stories as the individual's own experience. ${ }^{8}$ It is analogous to the difference between playing with a Tamagotchi or Second Life and observing someone else playing. These games create a world that never pauses even when users have stopped playing. Game players, unlike game observers, grow emotionally attached to their virtual

\footnotetext{
${ }^{8}$ Based on my hypotheses about networked time-consciousness, one would expect a high resistance to switch from one media platform to another. However, if this expectation is correct, it would seem difficult to explain how races would collectively fled between Facebook and Myspace (Boyd, 2012). In one possible argument, a networked individual may feel especially disgusted with stories of another culture because she or he cannot bear the adoption of such stories as her or his own personal experiences. The individual would internalize the cultural conflicts in News Feed. Hence the conflict becomes even more unbearable.
} 
pets or avatars. Even when the players are working or studying, the well beings of virtual pets or avatars linger in the back of their minds. They recurrently feel the protention to return to the game console. Similarly, a Facebook user is emotionally attached to the personalized News Feed page and recurrently feels the protention to access Facebook.

\section{Protention of Posting Status on Facebook}

The analogy of Tamagotchi or Second Life is also relevant to the protention of posting status on Facebook. Just as the players in these games feel the protention to take care of their evocative objects, Facebook users feel the protention to take care of their Facebook avatars by posting their personal status in real-time. Turning now to how Facebook users develop the protention to post status, I begin by discussing their socializing needs and then compare the activity of posting on Facebook with the interactions in online forum or in other Web 2.0 services. Based on the comparison, I argue that specific thresholds of significance in an event determine a user's protention to post.

Initially, the secondary memory of reading friends' stories shapes the criteria of which types of posts are appropriate. The number of comments and "Likes" or other positive emoticons is a voting system about the acceptability of a post. This system simulates the socializing dynamics of social acceptance or rejections. Participation in this online version of socializing may lead to a feeling of social obligation and subsequently the protention to post. In other words, this protention is driven by an underlying desire to satisfy socializing needs.

Nevertheless, this desire does not by itself lead to the frequent acts of posting. Rather, the act of posting on Facebook is typically triggered by specific events or experiences. The type of experiences is similar to posting status on Picasa or a personal blog, but different from posting in an online forum. When users post messages in an online forum, they participate in discussion threads most of the time. This participation involves responding to or commenting on some previous message. Thus posting in an online forum usually stems from the experience of reading messages. The protention criteria are certain phrases or comments that trigger reactions. In Facebook, users do not post status as direct responses to friends' stories. Rather, posting status stems from some experience in the life-world. ${ }^{9}$ By posting, users can share their feelings, their opinions about an online text or videos, or their personal experiences throughout the day. Therefore, the protention criteria for posting status on Facebook are specific attributes about an experience in the life-world.

Even though, for both Facebook and Picasa, experiences in the life-world bring about the act to post, the protentions to post in these systems are still distinguishable. Their temporalities are different. Unlike a Picasa album or a personal blog, the News Feed page exhibits a networked temporal collage. The page is intertwined with friends' stories, and users adopt these stories as constituents of their own experiences. When they share a post, they reflexively anticipate that friends would view their News Feed stories. If users share posts infrequently, the flood of friends' stories would suffocate their personal temporalities. Therefore, they need to post frequently in order to guard personal retentions and identity.

\section{Political Analysis}

Up to this point in this paper, I argue that users develop a networked temporality in their interactions with the News Feed page. When individuals engage in non-Facebook activities, they do so with

\footnotetext{
9 "Experiences in the life-world" mean not only non-mediated experiences, but also those in the non-Facebook cyberspace such as web browsing or online games.
} 
the flux of friends' postings in the back of their minds. This mental state results in the protention of reading News Feed stories and of posting status on Facebook. While the preceding sections focuses at the level of an individual, it is also politically significant at a macro level of society. As Castells remarks, "[t]he fundamental power struggle is the battle for the construction of meaning in the minds of people" $(2012$, p. 5). When an institution tempers with the collective temporal and spatial frames in a sociocultural context, that tempering has a political implication. Giddens, Harvey, Castells, and Stiegler all recognize this political significance..$^{10}$ In the following, I shall examine the political implications of the News Feed feature. I first look at how this feature encourages the constant acceleration in the pace of life, a notable characteristic of capitalism. I then discuss how online surveillance and the Big Data technology reconfigure the spatial and temporal power relations of the News Feed feature.

According to Harvey, one consequence of capitalism is the omnipresent pressure to accelerate the pace of livings. In The Conditions of Postmodernity (1989), Harvey argues that capitalism has been characterized by "continuous efforts to shorten turnover times, thereby speeding up social processes while reducing the time horizons of meaningful decision-making" (p. 229). Historically, to achieve this omnipresent incentive to accelerate turnover times, capitalists invested in technologies to overcome spatial and temporal barriers. Harvey identifies several historical moments in the $19^{\text {th }}$ and $20^{\text {th }}$ century in which new technology overcame spatial barriers to shorten turnover time. Harvey calls this phenomenon the space-time compression.

The acceleration in Facebook is different from Harvey's examples. Facebook overcomes the spatial barriers between friends and relatives distributed across the globe, resulting in a spatial reconfiguration of social relations. This overcoming of spatial barriers is unable to shorten the turnover times of industrial production. Yet, under the same capitalist pressure for profit growth based on online advertising, Facebook still holds an omnipresent incentive to accelerate the frequency of usage. Instead of overcoming spatial barriers to shorten turnover times, Facebook intends to overcome users' temporal barriers in order to shorten their Facebook-idle times. By temporal barriers, I mean the temporal frames that have been inscribed by the institutions of education and media.

The ephemeral temporality of the News Feed feature is complicit in this capitalist intention. As I previously argue, the reading of News Feed stories generates an ephemeral temporal experience of a "rolling present." Users fear missing the evanescent "present" moments or they grow in curiosity over what friends recently post. The intensity of fear or curiosity is proportional to the quantity of friends' posts. Correspondingly, after the experiences of reading their News Feed pages, users realize that their own posts also belong to the ephemeral pasts. So they tend to post frequently to maintain their sense of being alive. This leads to a vicious cycle of perpetual acceleration. ${ }^{11}$

This perpetual acceleration translates to a heavy load on the server infrastructure. To support a heavy load with good performance and reliability, Facebook needs to invest a substantially higher cost in the development of software and server infrastructure. Facebook executives only make such investment when they recognize an even higher level of revenue. Until recently, this revenue comes from online advertising only. But under the pressure to monetize their services, they come up with

${ }^{10}$ For example, in the chapter on "timeless time", Castells argues that "social domination is exercised through the selective inclusion and exclusion of functions and people in different temporal and spatial frames" (Castells, 2010, p. 465).

11 It is interesting to note that Facebook foregoes the design principle of efficiency by adopting a user interface of a "rolling present." I can see two possibilities in their motives. First, users demand such ephemeral experience in postmodernity. It is what Frederic Jameson calls postmodern depthlessness, or the death of the self/subject (Jameson, 2012). Second, the 'rolling present' is a design that can ultimately generate a higher "hit" rate than a design with search efficiency. 
another source of revenue. With the Big Data technology, companies can now process and make meanings from the sea of personal private data. Online surveillance is now achievable.

In The Googlization of Everything (2011), Vaidhyanathan makes some astute observations about the changing forces at work in online surveillance. For instance, he characterizes online surveillance as the opposite to certain aspects of the panopticon effect. Using the example of a Panopticon, Foucault illustrates how the technique of surveillance induces fear into its disciplinary subjects (Foucault, 2004). Gradually, these subjects internalize the bodily regulation, and become increasingly conformant to certain social standards. Whereas Foucault suggests the regulation of a disciplined body under an invisible gaze, Vaidhyanathan argues that an individual is indifferent toward the possibility being watched. Thus online surveillance involves "not the subjection of the individual to the gaze of a single, centralized authority, but the surveillance of the individual, potentially by all, always by many" (p. 112).

From the perspective of surveillance, my previous analysis of Facebook deviates from both Vaidhyanathan's and Foucault's analyses. It suggests that the awareness of being watched within the domain of Facebook regulates individuals' activities in the life-world outside of the Facebook domain. Thus, contrary to Vaidhyanathan, individuals indeed care whether or not they are being watched. And contrary to Foucault, individuals want to be watched. Or more precisely, networked individuals want to make their presences felt under the watchful eyes on Facebook. Nevertheless, the surveillance-by-many on Facebook has a subtle similarity with Foucault's theory on surveillance. The technique of surveillance influences subjects even when they have escaped from the gaze of surveillance. They have internalized the gaze that disciplines their bodily instincts. Compared to Foucault's theory, Facebook users are also internalizing the awareness of surveillance-by-many. The awareness conditions not only their behaviors on Facebook, but also those in activities outside of Facebook.

Online surveillance also exhibits a marketing-oriented objective. As Vaidhyanathan describes:

ChoicePoint, Facebook, Google, and Amazon want us to relax and be ourselves. They have an interest in exploiting niche markets that our consumer choices have generated. These companies are devoted to tracking our eccentricities because they understand that the ways about which we are most passionate. (2011, p. 112)

Thus companies are devoted to tracking individuals' eccentricities. They have been researching and developing the Big Data technology to data mine and analyze the vast volume of personal data. ${ }^{12}$ Today, with the proven success of the technology, 13 commercial firms or government agencies can indeed track and analyze every post on Facebook. This technical development has two implications. First, the activities of posting yield higher revenue than the activities of viewing. While their

\footnotetext{
${ }^{12}$ The technology of data mining and analysis was developed in the early 1990s as modules of the customer relationship management (CRM) technology. The goal is to translate and transfer data from a number of databases into a single one. Analytic tools can then operate on a single database. Marketing department can use these tools to understand marketing trend. These customer databases are tiny in comparison with Big Data, which covers all online interactions by every Internet user. It was ambitious to convert CRM technology to operate on Big Data, and equally challenging to analyze in finer granularity. Marketing analytics are concerned with behaviors at the group level whereas the Big Data analytics drill down to behaviors at the individual level. Because of these technical difficulties, the feasibility of Big Data technology was far from obvious.

13 This technological success is evident after Edward Snowden disclosed the existence of numerous global surveillance programs.
} 
hit rate may translate into similar advertising revenue, posting activities also contribute to Facebook's algorithm to generate personalized advertisements. Facebook can sell these data to other commercial firms or government agencies. As a result, Facebook has an even higher incentive to accelerate users' posting activities, reiterating the theme of constant acceleration. Second, as users gain an increasing awareness about the capability of Big Data technology, the fear of surveillance resurfaces. This fear co-exists with the protention to post to Facebook. This co-existence generates an irresolvable tension in an individual. ${ }^{14}$

This Big Data technology also exemplifies how the production of a social space reconfigures power relations. Giddens' concept of time-space distanciation can be a useful theoretical framework for analyzing the emancipatory role of social media. Accordingly, social media, such as Facebook, overcome physical spatial barriers as they create social spaces of asynchronous communication outside the realm of state authorities. In Harvey's terminology, social media reduce the spatial and temporal friction between potential participants in a social movement. In the past, with the legal protection in data privacy and the technological difficulty in processing huge volume of data, state authorities or private corporations were unable to make meanings out of such data. In other words, the spatial distance between the News Feed features and authorities used to be substantial. But with the Big Data technology, this spatial distance is fading away. Metaphorically, this technology is constructing a virtual bridge, or a channel of access, that connects the News Feed database with authorities. This bridge overcomes the original spatial barrier and reconfigures the power relations associated with Facebook.

\section{Conclusion}

This paper attempts to analyze the temporality and spatiality of reading News Feed stories and of posting status on Facebook. I argue that individuals reading News Feed stories are adopting their friends' stories as if they belong to themselves, and call them "networked individuals." This is why, when individuals are not on Facebook, they are still influned by the time-consciousness of a network individual. When a significant event occurs, they feel the protention to post their feelings or hyperlinks about the event. The retention and protention of Facebook activities are the drivers behind the perpetual production and distribution of content at any time and in any place. In the introduction, I describe a friend's "always on" behavior during a skip trip, and this theory gives a possible explanation for this behavior.

The temporality and spatiality of Facebook is political significant in two different senses: the constant acceleration of capitalism and online surveillance. Drawing from David Harvey's argument in The Conditions of Postmodernity (1989), I argue that the constant acceleration of Facebook activities reifies users' daily activities by framing their protention to read and to post. As for online surveillance, Facebook users have to contend with the tension between their protention to post and their fear of surveillance. With the Big Data technology, a virtual bridge between the News Feed database and state or corporate authorities has been formed, and the spatial exclusion of institutions from Facebook is disappearing. The technology reconfigures the time-space distanciation and subsequently the power relations of this social space.

This paper analyzes Facebook as a theoretical critique of the capitalist system, of how Facebook activities reify human activities and commodify social relations. These analyzes bring to mind the

\footnotetext{
${ }^{14}$ David Harvey has also mentioned temporal and spatial tensions that were irresolvable in specific historical moments (1989). These turned into politically stressful moments when certain technological changes have triggered an intense acceleration of space-time compression.
} 
Marxist theory of commodity fetishism and Georg Lukács' theory of reification. But instead of the reductive representation of social relations as commodity relations, we have on Facebook the reduction of social relations to the specific affordances for communicating on the technical platform. This is why the critiques of Facebook in this paper are fundamentally cohesive with the critiques of a capitalist society. At the same time, herein lies the limitation of this paper. I have not dealt with the intersectionality between the critique of capitalism with the critiques of race and gender, such as how the constant acceleration of Facebook activities may affect the segregations of races. ${ }^{15} \mathrm{An}-$ other limitation is that, with its theoretical focus, further empirical research is required to substantiate its theories. Thus studies on intersectionality and empirical verifications point to potential areas of future research, which can help substantiate, refute, and enrich the arguments in this paper.

\section{References}

Boyd, D. (2012). White flight in networked publics. In L. Nakamura \& P. Chow-White (Eds.), Race after the Internet (pp. 203-222). New York, NY: Routledge.

Castells, M. (Ed.). (2007). Mobile communication and society: a global perspective: a project of the Annenberg Research Network on international communication. Cambridge, MA: MIT Press.

Castells, M. (2009). The rise of the network society (2nd ed.). Cambridge, UK; Malden, MA: WileyBlackwell.

Castells, M. (2012). Networks of outrage and hope: Social movements in the Internet age. Malden, MA: Polity Press.

Gelles, D. (2010, September 21). E-commerce takes instant liking to Facebook button. Financial Times. Retrieved from http://www.ft.com

Facebook Gets a Facelift. (2006, September 5). Facebook.com. Retrieved from https://www.facebook.com/notes/facebook/facebook-gets-a-facelift/2207967130

Foucault, M. (2004). Panopticism. R. Blom et al. (Eds.) The information society reader. New York, NY: Routledge.

Gergen, K. J. (1991). The saturated self: Dilemmas of identity in contemporary life. New York, NY: Basic Books.

Giddens, A. (1981). A contemporary critique of historical materialism. Berkeley, CA: University of California Press.

Giddens, A. (1984). The constitution of society: Outline of the theory of structuration. Malden, MA: Polity Press.

Harvey, D. (1989). The condition of postmodernity: An enquiry into the origins of cultural change. Cambridge, UK; Malden, MA: Wiley-Blackwell.

Hicks, M. (2010, August 6). Facebook Tips: What's the difference between top news and most recent?. Facebook.com. Retrieved from https://www.facebook.com/notes/facebook/facebooktips-whats-the-difference-between-top-news-and-most-recent/414305122130

Horkheimer, M., \& Adorno, T. W. (2002). Dialectic of enlightenment: Philosophical fragments (G.S. Noerr Ed., \& E. Jephcott, trans.). Stanford, CA: Stanford University Press.

Jameson, F. (2012). Postmodernism, or, the cultural logic of late capitalism. In M. G. Durham \& D. Kellner (Eds.), Media and cultural studies: Keyworks (2nd ed). (pp. 407-432). Cambridge, UK; Malden, MA: Wiley-Blackwell.

${ }^{15}$ For evidences of segregations of race on social media, see Race After the Internet (2012) by Lisa Nakamura and Peter Chow-White. 
Lefebvre, H. (1991). The production of space (D. Nicholson-Smith Trans.). Cambridge, UK; Malden, MA: Wiley-Blackwell.

Nakamura, L., \& Chow-White, P. (Eds.). (2012). Race after the Internet. New York, NY: Routledge.

Rainie, H., \& Wellman, B. (2012). Networked: the new social operating system. Cambridge, MA: MIT Press.

Stiegler, B. (1998). Technics and time, 1: The Fault of Epimetheus. (R. Beardsworth \& G. Collins, Trans.). Stanford, CA: Stanford University Press.

Stiegler, B. (2008). Technics and time, 2: Disorientation (S. F. Barker Trans.). Stanford, CA: Stanford University press.

Stiegler, B. (2010). Technics and time, 3: Cinematic time and the question of malaise. (S. F. Barker Trans.). Stanford, CA: Stanford University Press.

Turkle, S. (1997). Life on the screen: identity in the age of the Internet. New York, NY: Simon \& Schuster.

Vaidhyanathan, S. (2011). The Googlization of everything (And why we should worry). Berkeley, CA: University of California Press.

Xin, C., Glass, G., Feenberg, A., Bures, E., \& Abrami, P. (2010). From Active Reading to Active Diaologue. In F. Pozzi, \& D. Persico (Eds.), Techniques for fostering collaboration in online learning communities: Theoretical and practical perspectives (pp. 300-318). Hershey, PA: Information Science Reference. 